\title{
MEDICIÓN DEL RIESGO CREDITICIO MEDIANTE LA APLICACIÓN DE MÉTODOS BASADOS EN CALIFICACIONES INTERNAS
}

\author{
Alejandro Vargas Sánchez y Saulo Mostajo Castelú
}

\section{RESUMEN}

En el presente documento se exponen los conceptos relacionados con el riesgo de crédito y los métodos utilizados para su medición. El objetivo principal fue describir los Métodos Basados en Calificaciones Internas para calcular medidas de riesgo crediticio. La aplicación y análisis de resultados se realizó utilizando información financiera para un préstamo empresarial mediante un caso supuesto, así como una base de datos de operaciones bancarias simuladas que fueron manipuladas para desarrollar un modelo de score crediticio. Los resultados alcanzados mediante la aplicación de un Modelo Estructural y un Modelo en Forma Reducida, mostraron diferencias importantes en el nivel de Previsiones, respecto a los requerimientos establecidos en la normativa legal aplicable a Entidades Financieras reguladas en Bolivia. El trabajo reveló que la aplicación de modelos avanzados para la medición de riesgo, requiere estimaciones adecuadas sobre la volatilidad de un negocio y modelos de score crediticio que permitan analizar profundamente una operación crediticia.

Palabras Clave: Riesgo de Crédito, Score Crediticio, Modelos Estructurales, Modelos en Forma Reducida, Pérdida Esperada, Probabilidad de Incumplimiento. 